\title{
Evaluation and Concept of Building Performance Towards Sustainability in Malaysia Higher Institutions
}

\author{
Natasha Khalil ${ }^{1}$, Husrul Nizam Husin ${ }^{1}$, Abdul Hadi Nawawi ${ }^{2}$ \\ ${ }^{1}$ Faculty of Architecture Planning and Surveying, University Teknologi MARA, Perak, Malaysia \\ 2 Faculty of Architecture Planning and Surveying, University Technology of MARA, Shah Alam, Malaysia \\ natas582@perak.uitm.edu.my
}

\begin{abstract}
The growing populations of students to higher institution is increasing year by year, therefore, it is importance to ensure that the building is well functioned throughout its lifecycle. Inevitably, the educational process may be interrupted if the building experiencea poor performance conditions, thus affect the students' academic achievement. Many studies have proved that there is the significance in providing holistic performance in educational buildings that able to improve the students' learning environment. 7his study is aimed to provide a new rating tool of building performance that is hoped to be used for Malaysia's higher educational buildings towards students' learning improvement.
\end{abstract}

Keywords: higher institutions; performance evaluation; performance concept- learning efficiency

eISSN 2514-751X @ 2 2018. The Authors. Published for AMER ABRA cE-Bs by e-International Publishing House, Ltd., UK. This is an open-access article under the CC BY-NC-ND license (http://creativecommons.org/licenses/bync-nd/4.0/). Peer-review under responsibility of AMER (Association of Malaysian Environment-Behaviour Researchers), ABRA (Association of Behavioural Researchers on Asians) and cE-Bs (Centre for EnvironmentBehaviour Studies), Faculty of Architecture, Planning \& Surveying, Universiti Teknologi MARA, Malaysia.

DOI: https://doi.org/10.21834/aje-bs.v3i6.239 


\subsection{Introduction}

According to Fien et al., (2010), several universities had signed a 10-point action plan for incorporating sustainability and environmental literacy in teaching, research, operations and outreach at colleges and universities Inevitably it shows that sustainability in universities is vital to prolong the education system Higher learning institutions generally occupy large land area and a growing populations year by year As stated by Olanrewaju (2010), transmitting knowledge and culture is one the business agenda of universities Various activities which are not limited to education and research activities alone is conducted in the campus involving students as the dominant occupants of higher institutions Therefore, the academic and non-academic activities resulted in two significant ways which are direct and indirect impacts on the conditions, environment and sustainability Wong and Jan (2003) stressed that building evaluation is the first priority as it is imperative to know the status quo of the building before one can effectively predict future building performance Seeing this importance, the evaluative criteria derived from the occupants in educational buildings is need to be measured for its general condition and suitability for education.

In the current situation, where people concerns about building performance and sustainability, occupants demand to have priority in terms of comfortability to use and utilize the facilities and services as itmust be fit for the purpose of the user The educational process and learning activities may be interrupted due to poor building conditions Hence, there is a need to adopt the application to evaluate the performance of technical aspects of higher institutions For Malaysia's context, to proposed appropriate framework, analytical study must be reviewed from the experiences of other countries such as New Zealand, the United States of America and Canada regarding strategies that they adopted to address performance evaluation and its impact on students' learning efficiency Test is needed to seek the relevance of the proposed strategies to the needs of Malaysia Therefore, this study is purposely conducted to propose a new guideline to evaluate building performance as a rating tool, by using behavioral suitability The evaluation survey is limited to the students of the higher educational building, focusing in five (5) public institutions (IPTA) in Malaysia The aspect of building performance that needs to be drawn is generally in terms of technical aspects (superstructure and the architectural elements

\subsection{Issue Statement}

The learning environment in the higher institutions is generally different from the primary or secondary education Every higher institution is built to serve the tertiary education to students based on the various programmes offered and therefore, the design and facilities provided in the higher institutions must suit the objectives of the education programmes However, the assessment of the building condition does not explicitly address the educational inadequacy of the academic buildings that are the relationship between the physical condition of the schools and the various educational goals and activities that take place within the building (Doidge, 2009) Problems in educational buildings include various aspects such as building designs, technical building elements, rooms, facilities, safety aspects, indoor and outdoor environmental problems and noise pollution According to Altan (2010), the increasing number of students and learning activities in higher institution has contributed to the 
inefficient of energy use and these may decrease the total performance system of the building year by year

There are many terms used in evaluating the building performance However, O'Sullivan et al (2004) asserted that most building performance assessment is done at the design stage of a building through the use of simulation tools, some assessment is carried out at the construction and commissioning stage by means of commissioning tests O'Sullivan et al (2004) added that thereafter, there is little or no assessment carried out at the operation and maintenance phases of a buildings lifecycle Many building practitioners are not aware of the requirement of building evaluation after it is occupied Despite many research done towards building performance in higher educational buildings, the standard guideline of the building rating tool towards improving students' learning efficiency is not yet introduced in Malaysia Many studies are delineated to the environmental conditions of the building, such as visual aspects, thermal comfort and air movement, but, none of the research is merely done on the technical aspects of the building element (superstructure and architectural elements)

For instance, Ambu et al (2008) develops a general guideline of an indoor environment quality for any types of building and analyse its impact on health purposes, but the study does not relate the specific guideline to be used towards the students' learning efficiency Another similar study conducted by Sohif et al (2009) address the concept of an indoor environment and its sustainability in the campus by reviewing the used practices, the organizational approach and measurement of technical improvement towards sustainability $\mathrm{He}$ suggested that universities must preserve the environment, stimulate economic growth, and improve the well-being of the surrounding community, but, the study does notprovide any new method achieving the sustainability aspects concerned Ideally, the initial existence of building starts from the concept of design and the provision of building elements, not merely on the environment Hence, the suitability of buildings in terms of technical aspects needs to be captured earlier in order to suit the occupants' comfortability

\subsection{Performance Evaluation And Its Concept}

The goal of building performance evaluation in higher educational buildings is merely to improve the building delivery process which incorporates an efficient evaluation process into the daily learning activities Hence, it will support all the stages of the building delivery system such as the facilities plan, design, construction and operation towards its improvement for students' learning efficiency The major focuses of such evaluation are for better understanding on the impact of early design delivery decisions on long term building efficiency, study the impact of building delivery processes also study the decisions on customer response both initiallyand over the life cycle of the building

\section{Performance Evaluation in Higher Institutions}

Education process is essential in human life as to ensure that knowledge able to be delivered in well manner Amaratunga and Baldry (1998) revealed that assessment of the building performance of institutions delivering higher educational services has become a matter of particular interest to the government seeking to increase the effectiveness of educational provision and maximise value for money Lynch and Peters (as cited Amaratunga and Baldry, 
1998) in their study asserted that there is an increasing awareness to improve building performance whereby there is a direct link between the quality of the work place and the effect it has on the performance of its most critical resource, i e employees This can be applied as well at the higherinstitution, whereby, if there is a poor quality of building performance and if the technical delivery system is deteriorated, it may reduce the students' efficiency in their learning activities A preliminary study conducted by Natasha et al (2010) shows that $40 \%$ of the students in one of the higher institution in Perak, Malaysia agreed that their learning process can be affected by poor provision of the indoor environment The analysis has shown that if a higher educational building experiences poor environmental conditions, it will demotivate the students during the learning process, thus reduce the quality of students' achievement (refer to Fig 1)

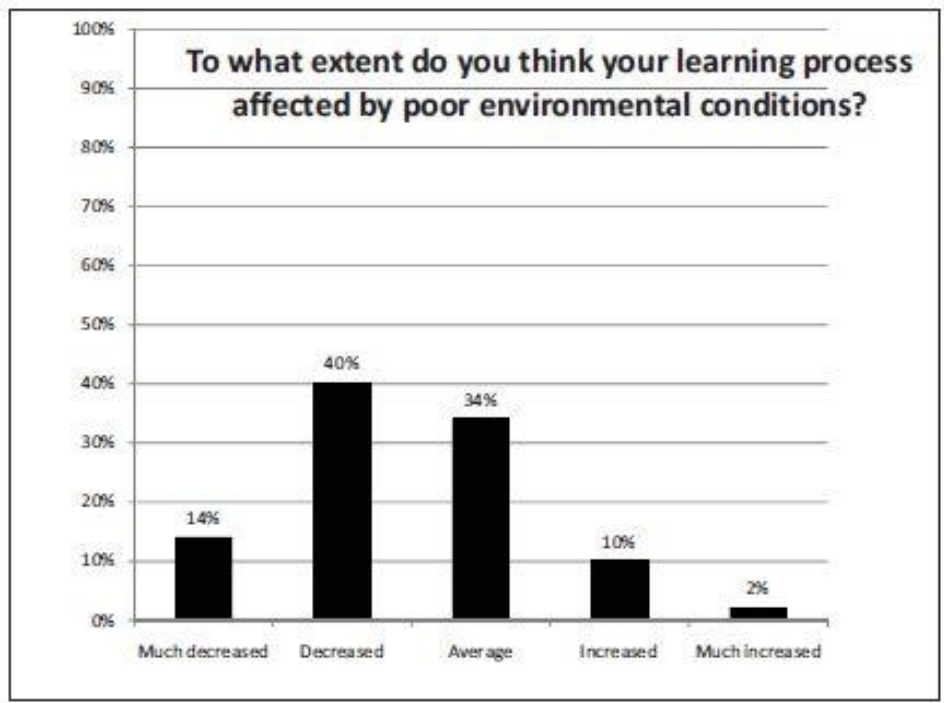

Figure 1: Assessmentofstudent'slearning processaffected by poor environmental conditions Source: Natasha et al., (2010)

The satisfaction parameters of the occupants; especially the academicians and students must be addressed as to fulfill their requirements and expectations while they are at the academic buildings A study conducted by Karamera (2003) found that students' performance is significantly correlated with the satisfaction of the academic environment and services received $\mathrm{He}$ also found in his study that the existence of the professional development programs and internship opportunities are associated with better academic performance With regard to the background variables, he found a positive effect of high school performance and school achievement while there was no statistical evidence of the significance of the association between the family income level and the academic performance 
In higher institutions, as stated by Beicher (1997), it is convinces to advocate that universities take a more progressive commercial approach to resource allocation than has been the case in the past It is suggested that development of building performance evaluation in higher institutions not only able to resource allocation in universities, but also to lead to development of approaches for commercial competitive advantage According to Gupta et al (2005), higher education institutions require a number of support services in order to achieve their primary missions - research and teaching Hence, both of these missions must be integrated to maintain a sustainable environment and without a doubt, the delivery of building performance throughout the building lifecycle

\section{The Concept of Performance Assessment}

The question may rise when it is pertaining to the assessment of performance in higher institutions is that, how "performance" is measured? Amaratunga and Baldry (1998) stated that the performance concept in the building process views buildings as dynamic entities and indicates a comprehensive attitude towards the management of buildings In simple terms, performance can be measured by comparing the attributes or criteria in the building Results derived from the assessment are used as a lesson learned or feed back to improve the evaluated building performance notonly in the planning aspects, but also in programming, design and construction of future buildings As cited by Amaratunga and Baldry (1998), building performance has been defined in British Standards (BS) 5240 as behaviour of a product in use In Singapore, Wong and Jan (2003) has introduced a framework namely Total Building Performance (TBP) as a performance assessment in higher educational buildings This framework is used as an evaluation to understand the critical balance needed to simultaneously ensure all building performance in terms of physical and environmental conditions and investigate whether the academic institution provide a conducive learning environment for the students This assessment concept applied to academic institutions that also helps to facilitate the provision of a healthy studying environment and facilities that are better customized to the needs of students and teachers in new schools The study concludes that it is evident that the study of the learning environment must be focused to more than one singular area of performance

Another performance assessment tool which is Post Occupancy Evaluation (POE) has been used extensively in UK, USA, New Zealand, Australia and Canada to evaluate any performance attributes in building, either for short term benefits, medium or long term benefits Preiser et al (1988) defined POE as the process of evaluating buildings in a systematic and rigorous manner after they have been occupied for some time The concept of POE is not only accepted to be used for higher educational building, but it can be used for any other types of buildings for any objectives, as being of value to the development and occupation process of buildings POE generally encompasses to a comprehensive review of the building details Over the last 20 years, a range of POE methods have been developed and their systematic application has demonstrated a huge potential not only to reduce the financial and environmental costs, but also to improve the quality of life, comfort and productivity of building (Nicol and Roaf, 2005) Natasha and Abdul Hadi (2008) has introduced a framework of POE consisting vital steps that need to be consider when 
evaluate the performance of buildings In order to suit with the primary mission of higher institutions, the framework is suggested to inculcate the performance elements that able to improve the learning environment

As described before, the aspects of building performance in higher institutions is not limited to physical conditions and functional aspects, but also towards the environmental issues in academic buildings In UK, the performance assessment tool used to evaluate the environmental conditions in higher institution is introduced as Building Research Establishment Environmental Assessment Method (BREEAM) According to James and Hopkinsons (1994), BREEAM has over a decade's track record and widely used in the UK private sector It works by creating a specification for a building with a number of individual criteria (grouped into Management, Energy, Health and Well-being, Pollution, Transport, Land use, Ecology and Materials) Each criteria are weighted in importance by having credits or points attached to it (typically between 1 and 5) The only barriers that mitigate this evaluation tool are seemed to knowledge expertise and definitely, cost for such evaluation BREEAM is found to be more delineated on sustainability issue in higher institution, but the apparent weakness of this tool is it does not address the social and ethical aspects of sustainability in relation to buildings

Based on the literature and studies derived from the precedent research, there is a significant correlation in providing a good and quality building performance that can engage the whole performance of the tertiary students in higher institutions Hence, this study is aimed to generate a new guideline of building performance rating tool, with regards to the improvement of the learning environment and students' learning efficiency

\subsection{Objectives of Study}

The objectives for this study are;

1. to investigate the concept of building performance evaluation in higher institutions

2. to determine the performance criteria in higher academicinstitutions

3. to develop a new guideline of building performance rating tool, specifically for Malaysia's higher institution

4. to testthe proposed guideline; by correlating the building performance criteria and the occupants' satisfaction level.

\subsection{Methodology}

Both, qualitative and quantitative methods are used as a research method to achieve the objectives of this study and to answer research questions In qualitative, the study is delineated to determine a theoretical basis and the concept of building performance evaluation and analyze precedent application of such evaluation All of the factors and constraints of the building performance is determined, and the standard provision of the technical performance in academic building is also analyzed From the study and analysis, a proposed guideline of building performance evaluation as a rating tool is suggested to be used for higher educational buildings, with regards to the effect of students' learning 
efficiency in Malaysia

In quantitative, data are obtained through the research instruments, i e visual inspection and questionnaire survey, as to seek the effectiveness of the proposed guideline The hypotheses for the findings are defined and the performance problems occurred in all building samples will be photographed clearly in order to proof the problem occurrence and for record purposes All collected data are analyzed to get the findings of the research and to achieve the research objectives The rating percentage will be presented to reveal the respondents' perception level towards the technical aspects of the buildings and data from the samples are analyzed using SPSS (Social Package Statistical Science) and the findings are documented

\subsection{Scope and Sampling of Study}

Probability sampling is used for this study and the respondents are randomized For the purpose of this study, this type of sampling is used to achieve the third objective; to test the proposed guideline by determining the technical performance aspects of the higher institutions and determining the students' satisfaction level

\subsection{Building Samples - Higher Educational Institutions}

There are five public institutions (IPTA) identified as the subject for the case study i e University of Malaya (UM), National University of Malaysia (UKM), University of Science Malaysia (USM), University of Technology Malaysia (UTM) and University of Technology MARA Malaysia (UiTM) The selection of the buildings is based on the accessibility of the buildings, location, problems or issues raised in those buildings and the reliability of the occupants This helps to clarify the general overview of the building performance The institutions are selected in order to give different perspectives of the issues related to the aspects of the building performance.

\subsection{Random Sampling - Students as the Respondents}

Random sampling is used in distributing the questionnaire to the respondents, which is only given to the occupants of the building, based on the selected building samples This research targets to obtain 500 samples of respondentsand the population of the respondentsis identified from the building samples that need to be drawn The percentage of the respondent's population for this research is $100 \%$ students Random sampling is as it is able to obtain various probability of satisfaction from different genders of respondents, their perception towards the performance of the technical aspects of building, their experiences and hours spent in the selectedbuildings

\subsection{Significance of Study}

The proposed rating tool has a significant role in the educational agenda and academic programmes by providing opportunities for the improvement of building performance and the relationships of the behaviors among the users it is hoped that based on this study, it would be able to be a vital contribution in extending and improving the design consideration related to the functional requirements of the educational buildings in Malaysia The rating tool also 
may be suggested to accomplish a systematic way that is able to collect all data and information in the buildings It able to enhance the quality of the building performance by addressing the sensitivity and the changing needs of the occupants It is also hoped that the rating tool able to improve the building technical performance towards a more effective learning process.

\subsection{Conclusion}

From the literature review above, the empirical research applying the theories of performance evaluation in higher institutions is pertaining to the issue of building technical elements, environmental conditions, facilities, space planning and layout of the area It is inevitable that by providing opportunities for the improvement of building performance and the relationships of the behaviors among the users, the performance rating tool as intended to be proposed in this study able to provide a significant role in Malaysia's construction industry It is hoped that based on this study, it helps to achieve building sustainability throughout the building delivery process and its lifecycle as well as improving the design consideration related to the functional requirements of the educational buildings in Malaysia It also helps to enhance the quality of the building performance by addressing the sensitivity and the changing needs of the occupants and at the same time, improve technical performance towards a more effective learning process.

\section{References}

Altan, H (2010) Energy efficiency interventions in UK higher education institutions Journal of Energy Policy, 38, $7722-7731$

Amaratunga, D and Baldry, D (1998) Appraising The Total Performance of Higher Educational Buildings: A Participatory Approach Towards ( Knowledge-base System. Proceedings of Construction andBuilding Research Conference (COBRA) Retrieved June 6, 2010 from http:// www rics org/site/scripts/download_info aspx

Ambu,S , Chu,W L , Mak,J W , Wong,S F , Chan, L L and Wong, S T (2008) Environmental Health and Building Related IIInesses Journal of Science, Medicine and Education, 2 (1), 11 - 18

Beicher, R G (1997) "Corporate Objectives, Facilities, Measurement and Use: AUniversity Model" Proceedings of RICSand Construction and Building Research Conference (COBR() Conference, Portsmouth, UK

Doidge, C (2001) )ost-occupancy eualuation. Retrieved November 15, 2009 from http://cebe cf ac uk

Fien, J , Maclean, R and Park, M G (2010) Work, Learning and Sustainable Deuelopment - Opportunities and Challenges. Retrieved April 21, 2010 from http://www springerlink com/content/978-1-4020- 81934 \#section=126126\&page $=1 \&$ locus $=0$

Gupta, A , Herath, S K, and Mikouiza, N C (2005) Outsourcing in Higher Education: An Empirical Examination International. ?ournal of Educational Management. 19 (5), $396-412$

James, P and Hopkinson, P (2004) Sustainable Buildings Can Beneßt HigherEducation-(Brießng)aper. 
RetrievedJanuary10,2011from www heepi org uk

Karemera,D (2003) The effects ofacademicenvironmentand background characteristics on students' satisfaction and performance: The Case of South Carolina State University's School of Business CollegeStudent Journal, 37 (2), $298-311$

Natasha, Kand Abdul Hadi, N (2008) Performance Analysis of Malaysia's Government and Public Buildings via Post Occupancy Evaluation

?ournal of (sian Social Science, H (9), $103-112$

Natasha, K , Husrul, N H \& Siti, R Z (2010) "Performance Evaluation of Indoor Environment Towards Sustainability For Higher Educational Buildings" Proceedings of $8^{\text {th }}$ International JTEFS/BBCC Conference QSustainable Deuelopment. Culture. EducationV Paris, France, (17 - 19 May 2010)

Nicol, F and Roaf, S (2005) Post Occupancy Evaluationand Field Studies of Thermal Comfort Journal of Building Research and Information, 33(4), 338 - 346

O'Sullivan, D T J , Keane, M M , Kelliher, D and Hitchcock, R J (2004) Improving building operation by tracking performance metrics throughout the building lifecycle (BLC) Journal of Energy and Building, 36, 1075 - 1090

Olanrewaju, A A (2010) Quantitative analysis of criteria in university building maintenance in Malaysia Australasian Journal of Construction Economics and Building, 10 (3), 51 - 61

Preiser, W F E , Robinowitz,H Z \& White, E T (1988) )ost-Occupancy Eualuation. New York: Van Nostrand Reinhold

Sohif, M , Kamaruzzaman, S , Mazlin, M , Baharuddin, A , Halimaton, S H , Abdul Khalim, A R, Muhammad Fauzi, M Z , and Nurakmal, G A (2009) Managing Sustainable Campus in Malaysia-Organisational Approach and Measures European Journal of Social Sciences, 8 (2), 201-214

Wong, N H and Jan, W L S (2003) Total building performance evaluation of academic institution in Singapore Journal of Building and Environment, 38, $161-176$ 